\title{
Sequential Potassium Binding at the Extracellular Side of the Na,K-Pump
}

\author{
R. Bühler, H.-J. Apell \\ Department of Biology, University of Konstanz, Postfach 5560 M635, D-78434 Konstanz, Germany \\ Received: 30 August 1994/Revised: 27 January 1995
}

\begin{abstract}
Ion binding at the extracellular face of the $\mathrm{Na}, \mathrm{K}-\mathrm{ATP}$ ase is electrogenic and can be monitored by the styryl dye RH 421 in membrane fragments containing a high density of the Na,K-pumps. The fluorescent probe is noncovalently bound to the membrane and responds to changes of the local electric field generated by binding or release of cations inside the protein. Due to the fact that $\mathrm{K}^{+}$binding from the extracellular side is an electrogenic reaction, it is possible to detect the amount of ions bound to the pump as function of the aqueous concentration. The results are in contradiction to a second order reaction, i.e., a simultaneous binding of two $\mathrm{K}^{+}$ ions. A mathematical model is presented to discuss the nature of the two step binding process. On the basis of this model the data allow a quantitative distinction between binding of the first and the second $\mathrm{K}^{+}$ion. The temperature dependence of ion binding has been investigated. At low temperatures the apparent dissociation constants differ significantly. In the temperature range above $20^{\circ} \mathrm{C}$ the resulting apparent dissociation constants for both $\mathrm{K}^{+}$ions merge and have values between 0.2 and $0.3 \mathrm{~mm}$, which is consistent with previous experiments. The activation energy for the half saturating concentration of $\mathrm{K}^{+}$is $22 \mathrm{~kJ} / \mathrm{mol}$. Additional analysis of the titration curve of $\mathrm{K}^{+}$binding to the state $\mathrm{P}-\mathrm{E}_{2}$ by the Hill equation yields a Hill coefficient, $\mathrm{n}_{\mathrm{Hill}}$, of 1.33 , which is in agreement with previously published data.
\end{abstract}

Key words: Na,K-ATPase — Potassium binding Electrogenic transport - Cation binding site - Sequential binding - Activation energy

\section{Introduction}

The reaction cycle of the Na,K-pump consists of a sequence of ion binding and release reactions and confor-

Correspondence to: H.-J. Apell mational changes, by which cations are transported across the membrane against their electrochemical potential gradient. In conformational state $\mathrm{E}_{1}$, the ion binding sites are facing the cytoplasm and the protein binds three $\mathrm{Na}^{+}$ions. After the enzyme is phosphorylated by ATP and a spontaneous conformational transition to $\mathrm{E}_{2}$ occurs, the ions are transferred to the extracellular side and released into the aqueous phase. Under physiological conditions, the pump binds subsequently two $\mathrm{K}^{+}$ions from the extracellular medium and occludes them after dephosphorylation (Glynn, 1985; Läuger, 1991). The complete reaction cycle is shown in Fig. 1 in a modified version of the Post-Albers cycle (Läuger, 1991). Binding and release of $\mathrm{K}^{+}$ions to state $\mathrm{P}-\mathrm{E}_{2}$ occurs in an ordered sequence, as has been shown by a rapid filtration technique of Na,K-ATPase preincubated with ${ }^{86} \mathrm{Rb}^{+}$ (Forbush, 1987). Binding of $\mathrm{K}^{+}$is associated with charge translocation from the aqueous phase into the membrane. This electrogenic process produces a change of the electrical field inside the membrane dielectric (Apell 1989). Changes of the electric field can be detected by a fluorescence change of the noncovalently bound dye probe RH 421 (Bühler, Stürmer, Apell \& Läuger, 1991).

The simplest reaction scheme of the binding of two cations, $M$, to the phosphorylated enzyme in conformation $\mathrm{E}_{2}$ would be

$P-E_{2}+2 M \overleftrightarrow{K} P-E_{2} \cdot M_{2}$,

where $M$ holds for monovalent cations like the physiological relevant $\mathrm{K}^{+}$or its congeners, $\mathrm{Rb}^{+}, \mathrm{Cs}^{+}, \mathrm{NH}_{4}^{+}, \mathrm{Na}^{+}$, $\mathrm{Li}^{+}$. If linearity can be assumed between the change of fluorescence intensity and the number of bound $\mathrm{K}^{+}$ions, the fluorescence change $\Delta F(\mathrm{c})$, of the probing dye can be described in terms of the $\mathrm{K}^{+}$concentration of the solution:

$$
\Delta F(c)=\Delta F_{\infty} \frac{c^{n}}{K+c^{n}}
$$


where $\Delta F_{\infty}$ is the saturation value of the fluorescence change of $c \rightarrow \infty$. $c \equiv\left[\mathrm{M}^{+}\right]$is the concentration of the bound cation species, $K$ is the apparent dissociation constant and $n$ the Hill coefficient. If two cations are bound simultaneously as indicated in Eq. (1), the condition $n=$ 2 will hold. If sequential binding of ions occurs, a more detailed reaction scheme will describe this process:

$P-E_{2}+2 M \underset{K_{1}}{\leftrightarrow} P-E_{2} \cdot M+M \underset{K_{2}}{\leftrightarrow} P-E_{2} \cdot M_{2}$

To resolve the two reaction steps, a necessary condition is that they have properties which produce detectable differences. Those differences may be based on kinetic, spectroscopic or electric properties of the protein. Eq. (3) represents the simplest sequential model. A more complicated model could include for example a structural rearrangement of the sites between the two binding steps.

Different approaches were discussed in the literature to analyze the potassium binding mechanism and to determine corresponding kinetic parameters. However, due to the lack of a directly observable parameter representing the state of $\mathrm{K}^{+}$binding, only subsequent actions of the Na,K-ATPase were detected. Transmembrane fluxes of ${ }^{42} \mathrm{~K}^{+}$in red blood cells, which depend on the total reaction cycle, were measured as function of the extracellular $\mathrm{K}^{+}$concentration (Sachs \& Welt, 1967) and the results predicted a cooperative two-state model. Different approaches were detection of $\mathrm{K}^{+}-\mathrm{K}^{+}$exchange (Karlish \& Stein, 1982), of $p$-nitrophenylphosphatase activity (Gache et al., 1976) or activation of $\mathrm{Na}^{+}$efflux (Sachs, 1980). The most direct experiments so far are Forbush's studies of $\mathrm{Rb}^{+}$occlusion. He could determine the existence of a sequentially ordered fast and slowly accessible site by competition of radiolabeled $\mathrm{Rb}^{+}$ and unlabeled $\mathrm{K}^{+}$. His findings from kinetic experiments could be explained consistently by sequential binding in a "flickering-gate model" (Forbush, 1987, 1988).

In this paper, results from equilibrium titration experiments are presented, in which the occupation of the ion binding sites in phosphorylated states of $\mathrm{E}_{2}$ was measured by fluorescence changes of the dye $\mathrm{RH} 421$. This styryl dye detects changes of the local electric field induced by $\mathrm{K}^{+}$binding within the $\mathrm{Na}, \mathrm{K}$-ATPase in its $\mathrm{E}_{2}$ conformation. The simplest mathematical model of sequential binding, which described the experimental findings, is presented and applied. The deduced kinetic properties of the extracellularly presented ion binding sites are discussed.

\section{Materials and Methods}

$\mathrm{Na}, \mathrm{K}$-ATPase was prepared from the outer medulla of rabbit kidneys using procedure $C$ of Jørgensen (Jørgensen 1974). The specific ATPase activity was measured by the pyruvate kinase/lactate dehydro- genase assay (Schwartz et al., 1971) and the protein concentration determined by the Lowry method (Lowry et al., 1951), using bovine serum albumin as a standard. For most preparations the specific activity was in the range between 1900 and $2000 \mu \mathrm{mol} \mathrm{P}_{\mathrm{i}}$ per hr and $\mathrm{mg}$ protein at $37^{\circ} \mathrm{C}$.

The fluorescence styryl dye RH 421 was obtained from Molecular probes (Eugene, Oregon) and added from an ethanolic stock solution of $250 \mu \mathrm{M}$ to obtain a final concentration of $250 \mathrm{nM}$

$\mathrm{NaCl}$ and $\mathrm{KCl}$ were used in Suprapur quality (Merck. Darmstadt), all other reagents were of analytical grade. Phosphoenolpyruvate, pyruvate kinase, lactate dehydrogenase and $\mathrm{Na}_{2}-\mathrm{ATP}$ (disodium salt, Sonderqualität) were obtained from Boehringer, Mannheim. The solution of inorganic phosphate, $\mathrm{P}_{\mathrm{i}}$, was obtained by adding $50 \mathrm{~mm}$ ortho$\mathrm{H}_{3} \mathrm{PO}_{4}$ (Riedel-de Haen, Hannover) to a buffer containing $200 \mathrm{~mm}$ imidazole. The $\mathrm{pH}$ was then adjusted to 7.2 by addition of $\mathrm{HCl} .10 \mu \mathrm{l}$ of this solution were added to $1 \mathrm{ml}$ probe volume to get a final $P_{i}$ concentration of $500 \mu \mathrm{M}$. In control experiments was shown that addition of $2 \mathrm{~mm}$ imidazole to the buffer had no significant effect in the experiments.

Fluorescence measurements were carried out with a Perkin Elmer LS50B luminescence spectrometer. The thermostated cell holder was equipped with a magnetic stirrer. The excitation wavelength was set to $580 \mathrm{~nm}$ (slit width $15 \mathrm{~nm}$ ) and the emission wavelength to $650 \mathrm{~nm}$ (slit width $15 \mathrm{~nm}$ ). Under these conditions the phosphorylation of the $\mathrm{Na}, \mathrm{K}$-ATPase in the presence of $20 \mathrm{mM} \mathrm{Na}^{+}$yielded a relative $\mathrm{RH} 421$ fluorescence changes up to $100 \%$. RH 421 is an amphiphilic electrochromic styryl dye. It is thought to insert into the lipid domains of $\mathrm{Na}, \mathrm{K}$-ATPase membrane fragments. It does not respond to conformational transitions but detects changes of electric field strength inside the membrane dielectric (Bühler et al., 1991). Such changes in electric field strength are caused by binding or release of ions and/or by movement of charge inside the membrane. The fluorescence levels allow the discrimination between differently charged states of the enzyme. The relative fluorescence change is assumed to be a linear function of the change of the electric field (Grinvald et al., 1982; Bühler et al., 1991). Although there is general agreement that RH styryl dyes respond to changes of the electric field in the membrane, the mechanism is not explained completely so far (Grinvald et al., 1982; Bühler et al., 1991; Clarke 1992). While Bühler and colleagues (Bühler et al., 1991) attributed the main effect to an electrochromic mechanism. Clarke and colleagues (Clarke, Schrimpf \& Schöneich, 1992) presented evidence for additional voltage-sensitive aggregation of dye molecules. According to Clarke and colleagues the differences may be explained by higher dye concentrations they used compared to Bühler and colleagues (Clarke et al., 1992).

\section{Results}

The Post-Albers scheme (Fig. 1) describes states of the $\mathrm{Na}, \mathrm{K}$-ATPase having different numbers of cations bound or occluded. In a suspension of membrane fragments containing a high number of pumps, the resulting charge density within the membrane after addition of $\mathrm{K}^{+}$ions to the $\mathrm{P}-\mathrm{E}_{2}$ state is measured by the electrochromic dye RH 421 (Bühler et al., 1991). Na,K-ATPase membrane fragments were suspended in $1 \mathrm{ml}$ buffer containing (in mm): 30 imidazole, 1 EDTA and $5 \mathrm{MgCl}_{2}, \mathrm{pH} 7.2$, to a final protein concentration of $9 \mu \mathrm{g} / \mathrm{ml}$. The suspension was thermostated at the desired temperature and equilibrated with $250 \mathrm{~nm} \mathrm{RH} 421$. After the fluorescence intensity became stable, successively $20 \mathrm{~mm} \mathrm{NaCl}$ and 500 


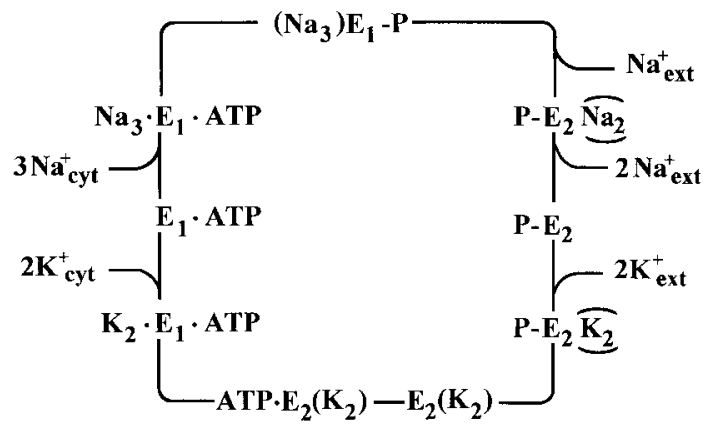

Fig. 1. Post-Albers scheme of the pump cycle of the Na,K-ATPase, adapted from Läuger (1991). $E_{1}$ and $E_{2}$ are conformations of the enzyme with binding sites facing the cytoplasm and the extracellular medium, respectively. In the "occluded"' states $\left(\mathrm{Na}_{3}\right) \mathrm{E}_{1}-\mathrm{P}, \mathrm{E}_{2}\left(\mathrm{~K}_{2}\right)$ and ATP $\cdot \mathrm{E}_{2}\left(\mathrm{~K}_{2}\right)$ the bound ions are unable to exchange with the aqueous phase. $\mathrm{P}-\mathrm{E}_{2}\left(\mathrm{~K}_{2}\right)$ and $\mathrm{P}-\mathrm{E}_{2}\left(\mathrm{Na}_{2}\right)$ indicate states, which may occlude ions upon binding of cardiotonic steroids. Dashes indicate covalent bonds and dots indicate noncovalent bonds. When the enzyme is phosphorylated by ATP in state $\mathrm{E}_{1}, 3 \mathrm{Na}^{+}$ions become occluded $\left(\mathrm{Na}_{3} \mathrm{E}_{1} \cdot \mathrm{ATP} \rightarrow\left(\mathrm{Na}_{3}\right) \mathrm{E}_{1}-\mathrm{P}\right)$. The spontaneous transition to conformation $\mathrm{E}_{2}$ leads to the release of the $\mathrm{Na}^{+}$ions to the extracellular side. The subsequent binding of potassium initiates enzyme dephosphorylation and occlusion of $\mathrm{K}^{+}$ions. Low-affinity binding of ATP shifts the conformation to state $\mathrm{E}_{1}$ from which $\mathrm{K}^{+}$is released to the cytoplasm.

$\mu_{\mathrm{M} \mathrm{Na}}$-ATP were added and the fluorescence signal was monitored until the signal became stationary. In the presence of $20 \mathrm{~mm} \mathrm{Na}{ }^{+}$the pumps can be assumed to be essentially in the state $\mathrm{P}-\mathrm{E}_{2}$ after phosphorylation (Läuger, 1991). Subsequently $\mathrm{K}^{+}$was added in different aliquots of 5 or $10 \mu$ lo titrate $\mathrm{K}^{+}$binding in 15 steps to a saturating concentration, in which no further fluorescence decrease beyond the small dilution effect $(<1 \%$ per step) was observed. The fluorescence response to $\mathrm{Na}^{+}$, ATP and $\mathrm{K}^{+}$addition is shown in Fig. $2 A$. According to the properties of $\mathrm{RH} 421$ in the given experimental conditions, the fluorescence decrease indicated an increase of positive charge within the membrane/protein dielectric (Bühler et al., 1991). As a control an experiment is included, in which instead of $\mathrm{K}^{+}$only buffer containing $20 \mathrm{~mm} \mathrm{NaCl}$ was added. This trace represents the dilution and drift effects which had to be taken into account when the titration experiments were analyzed. The drift within each titration level was negligible, even upon addition of low concentrations of $\mathrm{K}^{+}$, when $\left|\Delta F / F_{0}\right|<1 \%$. The temperature was $20^{\circ} \mathrm{C}$. The fluorescence decrease caused by the titration with $\mathrm{K}^{+}$has been taken as a measure for the binding of $\mathrm{K}^{+}$to the states of $\mathrm{P}-\mathrm{E}_{2}$. The data points in Fig. $2 B$ represent the relative fluorescence change, $\Delta F / F_{0}$, versus the $\mathrm{K}^{+}$concentration. The reference fluorescence intensity, $F_{0}$, is the intensity level before addition of $\mathrm{K}^{+}$(cf. Fig. $2 A$ ). The data plotted in Fig. $2 B$ were corrected for the dilution of $\mathrm{RH} 421$ and $\mathrm{K}^{+}$ according to the increasing aqueous volume during the titration according to the control trace. Similar experiments were performed in the temperature range between
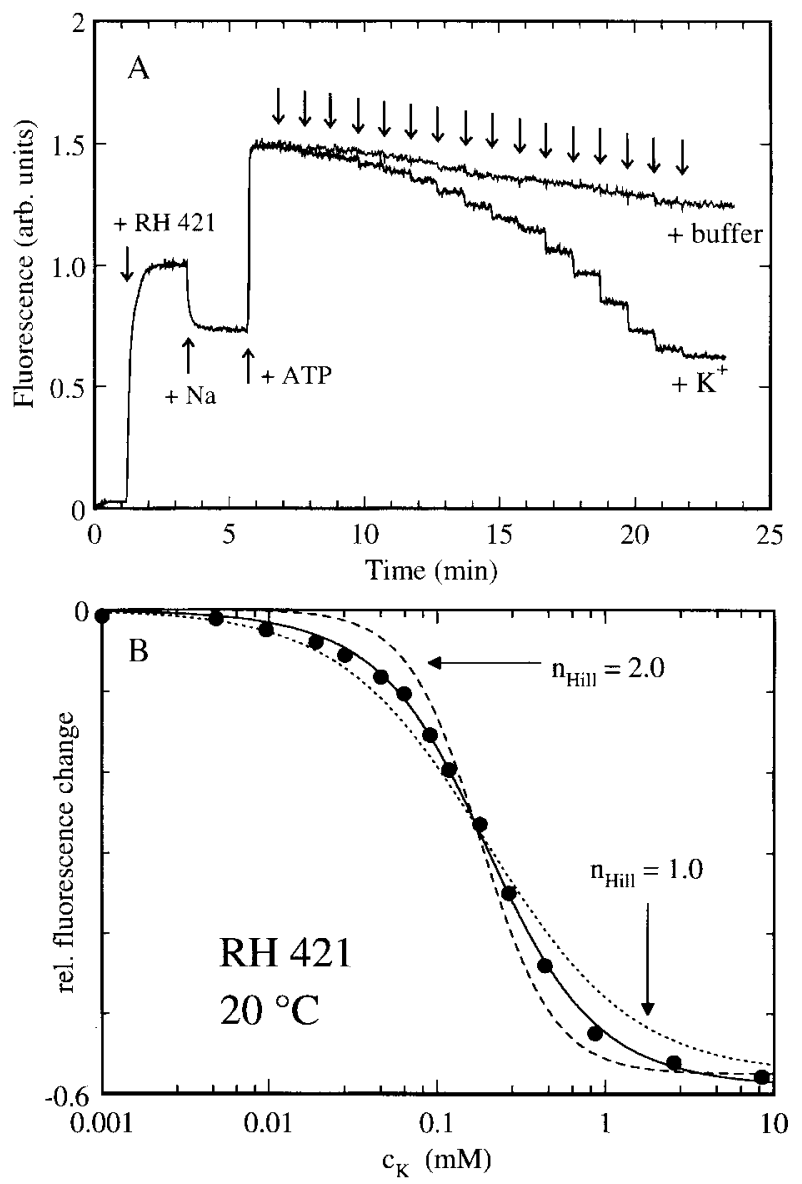

Fig. 2. Relative fluorescence changes of RH 421 labeled Na,K-ATPase membranes. (A) Open membrane fragments $(9 \mu \mathrm{l}$ protein $/ \mathrm{ml})$ were equilibrated with $0.25 \mu \mathrm{M} \mathrm{RH} 421$ in the presence of (in $\mathrm{mM}$ ): 30 imidazole, 1 EDTA and $5 \mathrm{MgCl}_{2}, \mathrm{pH} 7.2$. The temperature was $20^{\circ} \mathrm{C}$. The fluorescence was excited at $580 \mathrm{~nm}$ (slit width $15 \mathrm{~nm}$ ) and recorded at $650 \mathrm{~nm}$ (slit width $15 \mathrm{~nm}$ ). After having obtained a stable fluorescence level $20 \mathrm{mM} \mathrm{NaCl}$ and $0.5 \mathrm{~mm} \mathrm{Na}_{2}$-ATP were added successively to reach essentially state $P-E_{2}$. Subsequently buffer containing $\mathrm{KCl}$ was added in various amounts to titrated to the binding sites or $\mathrm{K}^{+}$free (bold trace). To demonstrate the dilution effects and the (negligible) fluorescence drift a control experiment is included, in which $\mathrm{K}^{+}$free buffer was added (light trace). $(B)$ The relative fluorescence changes, corrected for dilution effects, is plotted as function of the $\mathrm{K}^{+}$concentration in the solution. Equation (4) is fitted to the data points (solid line). Their error bars are smaller than the size of the points. A Hill function with a Hill coefficient, $\mathrm{n}_{\mathrm{Hill}}$, set to 1 (dotted) and 2 (broken line) do not fit the data. A fit of the Hill function resulted with a variable $n_{H i l l}=1.33$ which was not significantly different from the drawn continuous line (not shown).

$10^{\circ} \mathrm{C}$ and $35^{\circ} \mathrm{C}$ in intervals of $5^{\circ} \mathrm{C}$. Each experimental series was repeated at least four times. The experimental uncertainty of the data point was within the size of the symbol.

Control experiments were performed to demonstrate that the applied concentration of ATP was high enough to make sure that hydrolysis during the titration experiment did not reduce the concentration in a way that bind- 
Table. Analysis of $\mathbf{K}^{+}$binding after enzyme phosphorylation

\begin{tabular}{lllll}
\hline & $\mathrm{F}_{\infty}$ & $\mathrm{K}_{1} / \mathrm{mM}$ & $\mathrm{K}_{2} / \mathrm{mM}$ & $\mathrm{c}_{1 / 2} / \mathrm{mM}$ \\
\hline $10^{\circ} \mathrm{C}, 20 \mu \mathrm{M} \mathrm{ATP}$ & $-0.519 \pm 0.019$ & $0.176 \pm 0.099$ & $0.034 \pm 0.012$ & $0.072 \pm 0.006$ \\
$10^{\circ} \mathrm{C}, 500 \mu \mathrm{M} \mathrm{ATP}$ & $-0.537 \pm 0.019$ & $0.230 \pm 0.068$ & $0.090 \pm 0.023$ & $0.140 \pm 0.007$ \\
$10^{\circ} \mathrm{C}, 500 \mu \mathrm{M} \mathrm{P}_{\mathrm{i}}$ & $-0.409 \pm 0.011$ & $0.290 \pm 0.047$ & $0.224 \pm 0.022$ & $0.255 \pm 0.010$ \\
$15^{\circ} \mathrm{C}, 20 \mu \mathrm{M} \mathrm{ATP}$ & $-0.515 \pm 0.005$ & $0.157 \pm 0.023$ & $0.028 \pm 0.004$ & $0.065 \pm 0.002$ \\
$15^{\circ} \mathrm{C}, 500 \mu \mathrm{M} \mathrm{ATP}$ & $-0.519 \pm 0.005$ & $0.198 \pm 0.043$ & $0.121 \pm 0.014$ & $0.153 \pm 0.008$ \\
$20^{\circ} \mathrm{C}, 500 \mu \mathrm{M} \mathrm{ATP}$ & $-0.606 \pm 0.017$ & $0.169 \pm 0.031$ & $0.220 \pm 0.022$ & $0.192 \pm 0.009$ \\
$20^{\circ} \mathrm{C}, 500 \mu \mathrm{M} \mathrm{P}_{\mathrm{i}}$ & $-0.496 \pm 0.018$ & $0.316 \pm 0.017$ & $0.260 \pm 0.030$ & $0.286 \pm 0.013$
\end{tabular}

Enzyme phosphorylation by $20 \mu \mathrm{M}$ ATP or $500 \mu \mathrm{M}$ inorganic phosphate, $\mathrm{P}_{\mathrm{j}}$. Experiments have been performed as described in Fig. 2 with exception of the phosphorylation step, in which ATP concentration has been varied or ATP has been replaced by $P_{i}$.

ing to the low affinity binding site was significantly altered. When ATP was added in a concentration of 500 $\mu \mathrm{M}$ and no $\mathrm{K}^{+}$was added, the fluorescence level corresponding to state $\mathrm{P}-\mathrm{E}_{2}$ was maintained for times longer than at least $1 \mathrm{hr}$. The estimated ADP (and $\mathrm{P}_{\mathrm{i}}$ ) concentration at the end of a titration experiment was in the order of $50 \mu \mathrm{m}$, a concentration without significant inhibitory effect to the pump (Apell et al., 1986).

In the presence of $\mathrm{Na}^{+}, \mathrm{K}^{+}$and ATP the Na-pump runs through the physiological transport cycle (Fig. 1). $\mathrm{K}^{+}$ions are occluded and released to the intracellular side after conformational transition of the pump from $E_{1}$ to $\mathrm{E}_{2}$. $\mathrm{Na}^{+}$binding, phosphorylation and sodium release complete the cycle back to the state $\mathrm{P}-\mathrm{E}_{2}$. In the absence of $\mathrm{K}^{+}$the mainly populated state of the pump will be $\mathrm{P}-\mathrm{E}_{2}$ (Heyse et al., 1994). Addition of increasing amounts of $\mathrm{K}^{+}$will not only populate the states $\mathrm{P}-$ $E_{2} \cdot K$ and $P-E_{2} \cdot K_{2}$, but also other states around the cycle, mainly the states before the two rate limiting steps, ATP $-E_{2} \cdot\left(K_{2}\right)$ and $\left(N_{3}\right) \cdot E_{1} \cdot P$. Since the fluorescence intensity of these states will contribute to the signal, control experiments had to be performed to determine the contributions of subsequent partial reactions to the obtained apparent $\mathrm{K}^{+}$binding affinities, which were evaluated by the presented experiments. The reaction step, which follows $\mathrm{K}^{+}$binding is the dephosphorylation, $P-E_{2} \cdot K_{2} \rightarrow E_{2} \cdot\left(K_{2}\right)$. In forward direction it is a spontaneous reaction, which cannot be controlled by substrate conditions. However, in the presence of inorganic phosphate, $\mathrm{P}_{\mathrm{i}}$, the kinetic equilibrium can be shifted towards state $P-E_{2} \cdot K_{2}$. The subsequent conformational transition, $\mathrm{E}_{2} \cdot\left(\mathrm{K}_{2}\right) \rightarrow \mathrm{K}_{2} \cdot \mathrm{E}_{1}$, can be accelerated by high ATP concentrations, $\mathrm{K}_{2} \cdot \mathrm{E}_{1} \rightarrow \mathrm{K}_{2} \cdot \mathrm{E}_{1} \cdot \mathrm{ATP} \rightarrow$ ATP $\cdot E_{1} \cdot K_{2} \rightarrow$ ATP $\cdot E_{1}$ (Glynn, 1985). These functional properties of the Post-Albers cycle were used in additional experiments.

Experiments as shown in Fig. 2 were repeated in the presence of only $20 \mu \mathrm{M}$ ATP, which is a concentration in the range of the half-saturating concentration of the lowaffinity ATP binding in state $\mathrm{E}_{2} \cdot\left(\mathrm{K}_{2}\right)$. All other conditions were the same as described above. Under this con- dition the reaction $\mathrm{E}_{2} \cdot\left(\mathrm{K}_{2}\right) \rightarrow \mathrm{K}_{2} \cdot \mathrm{E}_{1}$ is the main rate limiting reaction step of the cycle with $1 \mathrm{~s}^{-1}$ (Glynn, 1985). Due to its low concentration, in these experiments ATP consumption played a major role. To control ATP consumption the following experiments were performed. After addition of $\mathrm{K}^{+}$in a concentration close to $c_{1 / 2}$ the fluorescence level was monitored. Due to the lack of ATP the fluorescence intensity returned to the initial level before addition of ATP after a certain period of time. These controls revealed that the available time was temperature dependent. Evaluable titration experiments could be performed in the presence of $20 \mu \mathrm{M}$ ATP therefore only at $10^{\circ} \mathrm{C}$ and $15^{\circ} \mathrm{C}$ (data not shown).

A third series of experiments made use of the observation that the Na,K-ATPase can be phosphorylated by $\mathrm{P}_{\mathrm{i}}$ in the absence of $\mathrm{Na}^{+}$(Glynn, 1985). In a buffer containing (in $\mathrm{mm}$ ): 30 imidazole, 1 EDTA and $5 \mathrm{MgCl}_{2}$ membrane fragments with a final concentration of $9 \mu \mathrm{g} /$ $\mathrm{ml}$ were equilibrated with $250 \mathrm{nM} \mathrm{RH} \mathrm{421.} \mathrm{Experiments}$ were performed at $10^{\circ} \mathrm{C}, 20^{\circ} \mathrm{C}$ and $30^{\circ} \mathrm{C}$. After a stable fluorescence intensity was reached $10 \mu \mathrm{l}$ of a $50 \mathrm{~mm}$ solution of $\mathrm{P}_{\mathrm{i}}$ was added. The fluorescence signal increased by approximately $50 \%$. Thereafter aliquots of $\mathrm{KCl}$ were added to titrate the binding sites. Since no $\mathrm{Na}^{+}$ and ATP were present in these experiments, the protein states in the upper half of the Post-Albers cycle could not be populated and contribute to the fluorescence signal. For comparison with ATP phosphorylation the results of the analysis of the experiments taken at $20^{\circ} \mathrm{C}$ are included in the Table.

\section{Theoretical Analysis}

Sequential binding of $2 \mathrm{~K}^{+}$ions to the extracellular binding sites of the protein according to Eq. (3) could be described by a mathematical model as explained in the Appendix. The assignment of fluorescence levels for the states $\mathrm{P}-\mathrm{E}_{2}, \mathrm{P}-\mathrm{E}_{2} \cdot \mathrm{K}$, and $\mathrm{P}-\mathrm{E}_{2} \cdot \mathrm{K}_{2}$ allowed the description of the relative fluorescence change of $\mathrm{K}^{+}$ binding as function of equilibrium dissociation constants, $\mathrm{K}_{1}$ and $\mathrm{K}_{2}$ 


$$
\frac{\Delta F}{F_{0}}=F_{\infty} \frac{\frac{\alpha c}{K_{1}}+\frac{c^{2}}{K_{1} K_{2}}}{1+\frac{c}{K_{1}}+\frac{c^{2}}{K_{1} K_{2}}}
$$

where $F_{\infty}$ is the saturation value of the fluorescence change, $c \cong\left[\mathrm{M}^{+}\right]$the concentration of the bound monovalent cation species, $K_{1}$ the apparent dissociation constant of the partial reaction $P-E_{2} \leftrightarrow \mathrm{P}-\mathrm{E}_{2} \cdot \mathrm{M}$ and $K_{2}$ that of $P-E_{2} \cdot M \leftrightarrow P-E_{2} \cdot M_{2} \cdot \alpha=\left(f_{1}-f_{0}\right) /\left(f_{2}-f_{0}\right)$ is the ratio of the fluorescence levels of $P-E_{2} \cdot M\left(F_{1}\right)$ and $P-E_{2} \cdot M\left(F_{2}\right)$. With parameters $\alpha, K_{1}$ and $K_{2}$ the half-saturating concentration $c_{1 / 2}$ can be calculated:

$c_{1 / 2}=K_{2}\left((0.5-\alpha)+\sqrt{\frac{K_{1}}{K_{2}}+\alpha^{2}-\alpha+0.25}\right)$

$c_{1 / 2}$ is defined by the condition $F\left(c_{1 / 2}\right)=F_{\infty} / 2$. For $\alpha=$ 0.5 Eq. (5) is reduced to

$c_{1 / 2}=K_{2} \sqrt{\frac{K_{1}}{K_{2}}}=\sqrt{K_{1} K_{2}}$

The solid line in Fig. $2 B$ shows a calculation of $\Delta F / F_{0}$ according to Eq. (4), fitted to the experimental data for $\alpha$ $=0.5$ and $K_{1}$ and $K_{2}$ optimized by a Marquardt fitting routine. The fitting program converged to the same set of parameters independent from the starting value, which were set in a range between 0.001 and $10 \mathrm{~mm}$. The fit of Eq. (4) was compared to the Hill plot with coefficients $\mathrm{N}_{\mathrm{Hill}}=1$ (dotted line) and $\mathrm{n}_{\mathrm{Hill}}=2$ (broken line). When the Hill coefficient was used as a fitting parameter in a least-square fit, $\mathrm{n}_{\mathrm{Hill}}$ was determined to be 1.33 . The corresponding curve is not presented in Fig. $2 \mathrm{~B}$, because it is almost identical to the solid curve of the fit of Eq. (4).

The temperature dependence of the parameters $c_{1 / 2}$, $K_{1}$ and $K_{2}$ is shown in Fig. $3 A$ and $B$. The values of $c_{1 / 2}$ have been obtained from the data, $K_{1}$ and $K_{2}$ were determined by fitting Eq. (4) to the data. A comparison of the experimentally obtained values of $c_{1 / 2}$ and of Eq. (6) gave agreement within the experimental errors. At each temperature four titration experiments were carried out and Eq. (4) was fitted to the data sets. Except of the temperature, the experimental conditions were the identical to those described for the experiments of Fig. 2. The data points in Fig. 3 represent the mean value of the respective parameters, the error bars indicate the standard deviation, $\sigma_{n-1}$. Fig. $3 A$ shows the temperature dependence of the half saturating concentration, $c_{1 / 2}$, of the relative fluorescence change after $\mathrm{K}^{+}$addition to the enzyme in state $P-E_{2}$. The activation energy of $E_{a}$ of $c_{1 / 2}$ was evaluated as $22 \mathrm{~kJ} / \mathrm{mol}$ by fitting the Arrhenius equation, Eq. (7), to the data (continuous line in Fig. 3A). $c_{1 / 2}(T)=A_{e}{ }^{-E_{i} / R T}$

Fig. $3 B$ shows the temperature dependence of the parameters $K_{1}$ and $K_{2}$.

The analysis of the $\mathrm{K}^{+}$binding experiments to state $\mathrm{P}-\mathrm{E}_{2}$ after phosphorylation by $20 \mu \mathrm{M} \mathrm{ATP}$ at $10^{\circ} \mathrm{C}$ and $15^{\circ} \mathrm{C}$ and after phosphorylation by $500 \mu \mathrm{M} \mathrm{P}_{\mathrm{i}}$ at $20^{\circ} \mathrm{C}$ was performed using Eq. (4) accordingly. The results are presented in the Table.

\section{Discussion}

In this paper we described experiments that allowed the measurement of $\mathrm{K}^{+}$binding to the Na,K-ATPase in its $\mathrm{E}_{2}$ conformation. As has been discussed in the literature, the affinity of the two-ion-binding sites is significantly higher for $\mathrm{K}^{+}$than for $\mathrm{Na}^{+}$in conformation $\mathrm{E}_{2}$ (Glynn, 1985; Forbush, 1987; Forbush, 1988; Glynn \& Richards, 1982). The sites are not necessarily equivalent and may be distinguished by the kinetics of ion release. Forbush carried out detailed studies of the kinetics of occlusion and phosphate-induced deocclusion of ${ }^{86} \mathrm{Rb}$ and was able to discriminate between a fast and a slowly accessible site (Forbush, 1988). According to his "flickering-gate model," release of ${ }^{86} \mathrm{Rb}$ from the slowly-exchanging binding site could be blocked by $\mathrm{K}^{+}$with an affinity of approximately $0.1 \mathrm{~mm}$. With this preposition sequential binding can be modeled and formalized as presented. In Eq. (4), the equilibrium dissociation constant of the first and the second cation, $K_{1}$ and $K_{2}$ respectively, are distinguished. The concentration dependence of the relative fluorescence change, $\Delta F / F_{0}$, as measured in this study depended only on both dissociation constants and the ratio, $\alpha$, of the contribution of states with one and two ions bound (Eq. A7). These parameters could be obtained by fitting Eq. (4) to the experimental signals.

In opposition to previously published studies, we did not monitor effects following $\mathrm{K}^{+}$binding from the extracellular side, e.g., enzymatic activity or transmembrane ion transport. Direct detection of $\mathrm{K}^{+}$binding is possible by the fact that it is an electrogenic process step (Läuger, 1991; Stürmer et al., 1991; Rakowski et al., 1991). Ion binding to the $\mathrm{Na}, \mathrm{K}-\mathrm{ATPase}$ in its $\mathrm{P}-\mathrm{E}_{2}$ state is proposed to consist of two steps: a migration of the ions from the surface through a narrow access channel or "ion well" to the site and a subsequent binding reaction (Sagar \& Rakowski 1994). The latter step may be slower than first.

In this study, we used Na,K-ATPase-containing membrane fragments labeled with the fluorescence dye RH 421, which detects mainly the movement of charges from the aqueous phase into the membrane dielectric and vice versa (Bühler et al., 1991; Läuger, 1991). The applied method is precise enough to discriminate between 
different numbers of cations bound to the extracellularly presented sites (Fig. 2B). It is less sensitive to charge movements inside the plain of adsorbed dye molecules in the membrane, as has been derived in the appendix of Bühler et al. (1991). If the dielectric length of the access channel between aqueous phase and binding sites is in the order of the distance of the adsorption plane of the dye from the membrane surface (or longer), then both ions will contribute with the same fluoresence change to the RH 421 signal. This would produce a strong constraint to the parameter $\alpha$, which then has to be close to 0.5 . Experimental indications which support this constraint were given by Heyse et al. (1994). They studied extracellular $\mathrm{Na}^{+}$binding to the $\mathrm{P}-\mathrm{E}_{2}$ state of the $\mathrm{Na}, \mathrm{K}$ ATPase by RH 421 experiments and found that the first two $\mathrm{Na}^{+}$ions, which bind to extracellularly presented sites, produced the same contribution to the fluorescence signal. The ions migrate over a dielectric distance of $20 \%$ of the total membrane thickness (Heyse et al., 1994). Since it is generally accepted that two of the $\mathrm{Na}^{+}$ and $\mathrm{K}^{+}$ions bind to the same protein moiety, we fixed $\alpha$ to a value of 0.5 . All states with two ions bound and all $\mathrm{E}_{1}$ states except $\left(\mathrm{Na}_{3}\right) \mathrm{E}_{1}$ and $\left(\mathrm{Na}_{3}\right) \mathrm{E}_{1}-\mathrm{P}$ exhibit the same level of fluorescence (Stürmer et al., 1991; Heyse et al., 1994). In addition we performed fits of Eq. (4) to the data, in which $\alpha$ could vary to obtain better fits with lower values of chi-square. However, the improvements were marginal and the values of $K_{1}$ and $K_{2}$ varied less than $10 \%$ (with a few exceptions).

To analyze the titration curves in the proposed way, two underlying assumptions had to be verified. The first assumption was that an equilibrium distribution between the three states $\mathrm{P}-\mathrm{E}_{2}, \mathrm{P}-\mathrm{E}_{2} \mathrm{~K}$ and $\mathrm{P}-\mathrm{E}_{2} \mathrm{~K}_{2}$ exists. This is valid provided all steps associated with extracellular $\mathrm{K}^{+}$binding are rapid compared to the reactions, which border the two states, and from which they are emptied: $\mathrm{P}-\mathrm{E}_{2} \rightarrow \mathrm{E}_{1}, \mathrm{P}-\mathrm{E}_{2} \rightarrow \mathrm{P}-\mathrm{E}_{2} \mathrm{Na}$ and $\mathrm{P}-\mathrm{E}_{2} \mathrm{~K}_{2}$ $\rightarrow E_{2}\left(K_{2}\right)$. According to Heyse et al. (1994), who presented a consistent set of rate constants of all involved reactions, the first two pathways fulfill the condition. The forward reaction, $\mathrm{P}-\mathrm{E}_{2} \mathrm{~K}_{2} \rightarrow \mathrm{E}_{2}\left(\mathrm{~K}_{2}\right)+\mathrm{P}_{\mathrm{i}}$, has a rate comparable to ion binding and has to be included in the discussion of the contributing reactions as can be seen from the $\mathrm{P}_{\mathrm{i}}$ dependence (Table). However, the next following reaction steps, $\mathrm{E}_{2}\left(\mathrm{~K}_{2}\right) \rightarrow \mathrm{ATPE}_{2}\left(\mathrm{~K}_{2}\right) \rightarrow$ $\mathrm{K}_{2} \mathrm{E}_{1} \mathrm{ATP}$, are sufficiently slow (Heyse et al., 1994). The second assumption is that no significant redistribution of pump intermediates occurs between the pool of $\mathrm{K}^{+}$-binding states and other states during addition of increasing concentration of $\mathrm{K}^{+}$. At low temperatures a redistribution has to be expected only between states $\mathrm{P}-$ $E_{2} K_{2}$ and $E_{2}\left(K_{2}\right)$, as was shown by the presence of inorganic phosphate, which drives this reaction backwards (Table). Since the specific fluorescence levels of both states is the same, they may be pooled and treated as one state after binding of two ions. The subsequent reaction
(ATP-binding and/or conformation change) is again sufficiently slow (Heyse et al., 1994). At temperatures above $20^{\circ} \mathrm{C}$ detectable effects were found as discussed below.

Titrations of the $\mathrm{K}^{+}$binding sites have been performed in the presence of saturating concentrations of ATP in the temperature range between $10^{\circ} \mathrm{C}$ and $35^{\circ} \mathrm{C}$ as shown exemplarily in Fig. $2 A$. The subsequent analysis is presented in Fig. $2 B$. The data can be fitted neither by a function, which describes ion binding without any cooperativity between both $\mathrm{K}^{+}$ions $\left(\mathrm{n}_{\mathrm{Hill}}=1\right)$, nor by simultaneous binding of both ions, as represented by a Hill function with $n_{H i l l}=2$. Using the Hill coefficient as a phenomenological parameter to find an optimum fit, we obtained $\mathrm{n}_{\mathrm{Hill}}=1.33\left(\mathrm{~T}=20^{\circ} \mathrm{C}\right)$. The corresponding curve is not included in Fig. $3 B$, since it was similar to the solid line, which represents the fit of Eq. (4). The phenomenological quantity $\mathrm{n}_{\mathrm{Hill}}$ does not explain any kinetical or mechanistic properties of binding, it should be taken only as an indicator of some kind of complex process.

The temperature dependence of experimentally determined values of $c_{1 / 2}$ and of the apparent affinities, $K_{1}$ and $K_{2}$ are presented in Fig. 3, as obtained by fitting Eq. (4) to the data. As a test of consistency, the experimentally and theoretically obtained values of $c_{1 / 2}$ agreed within the error bars in Fig. $3 A$ for all temperatures. The temperature dependence of the half saturating $\mathrm{K}^{+}$concentration obeyed the Arrhenius equation (Eq. 7) with an activation energy, $E_{A}$, of $22 \mathrm{~kJ} / \mathrm{mol}$. The activation energy under turnover conditions was determined to be $90-120 \mathrm{~kJ} / \mathrm{mol}$ (Marcus et al., 1986), which is significantly larger. The large discrepancy between the activation energy of the rate-limiting reactions under turnover conditions, $\left(\mathrm{Na}_{3}\right) \mathrm{E}_{1}-\mathrm{P} \rightarrow \mathrm{P}-\mathrm{E}_{2}\left(\mathrm{Na}_{2}\right)$ and $\mathrm{ATPE} \mathrm{E}_{2}\left(\mathrm{~K}_{2}\right)$ $\rightarrow \mathrm{K}_{2} \mathrm{E}_{1} \mathrm{ATP}$, and the $\mathrm{K}^{+}$-binding steps was an additional test that the observed effects were not controlled by subsequent steps. $K_{1}$ and $K_{2}$ differed not significantly at temperatures above $20^{\circ} \mathrm{C}$, but they diverged for lower temperatures (Fig. 3B). The error bars represent the standard deviation of different series of experiments, $\sigma_{n-1}$.

To explain the lower values of $K_{2}$ compared to $K_{1}$ in the temperature range between $10^{\circ} \mathrm{C}$ and $15^{\circ} \mathrm{C}$ and their agreement above $20^{\circ} \mathrm{C}$, one has to compare the reaction scheme of Eq. (4) with the simple model of the complete cycle in Fig. 4. After two $\mathrm{K}^{+}$ions are bound, the pump has the chance to run through the subsequent reaction cycle, which includes a whole series of reaction steps: occlusion of $\mathrm{K}^{+}$, the conformational transition to $\mathrm{E}_{\mathbf{I}}$ and ion release, and only after $\mathrm{Na}^{+}$binding, phosphorylation by ATP another conformational change to $\mathrm{E}_{2}$, the release of $\mathrm{Na}^{+}$brings the pump back to the reaction scheme of Eq. (3). At low temperatures the conformational change ATP $\cdot E_{2}\left(K_{2}\right) \rightarrow$ ATP $\cdot K_{2} E_{1}$ is so slow that the pathway through the cycle was negligible and the hardly revers- 

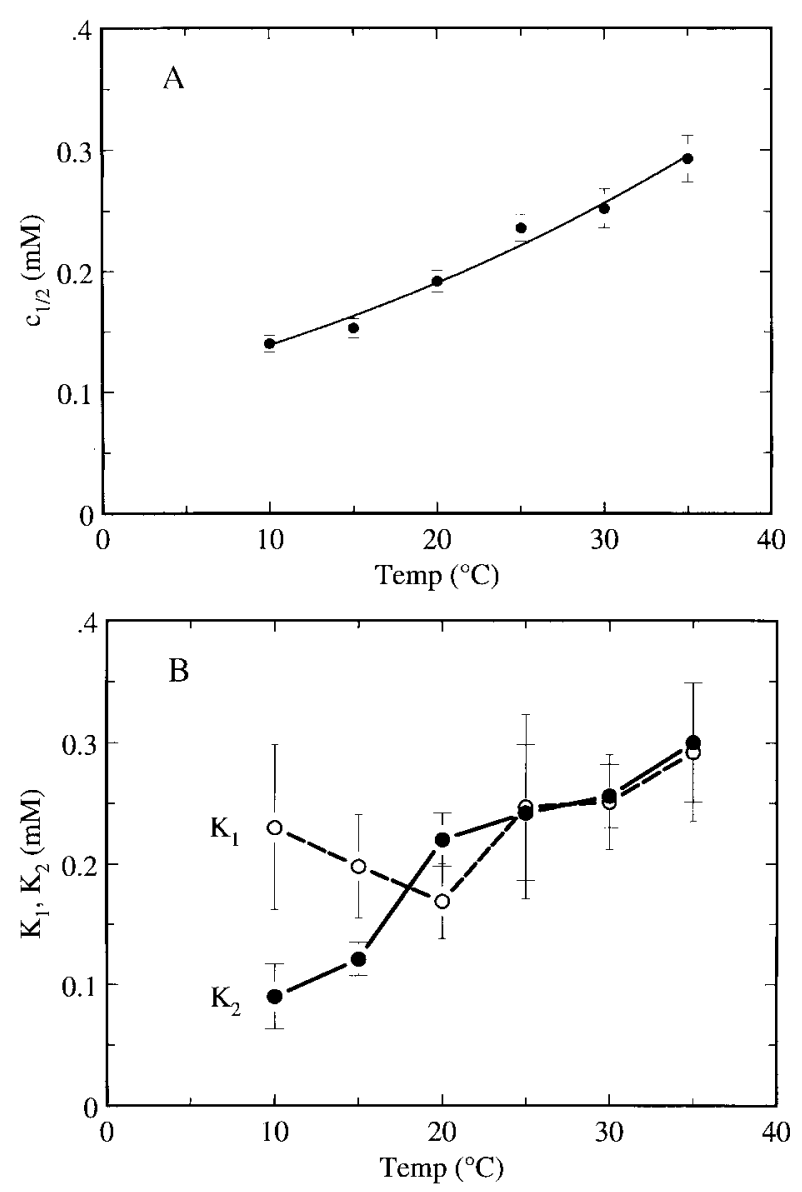

Fig. 3. (A) Half saturating $\mathrm{K}^{+}$-concentration, $c_{1 / 2}$ and $(B)$ apparent dissociation constants, $\mathrm{K}_{1}$ and $\mathrm{K}_{2}$ for the first and second $\mathrm{K}^{+}$binding site as a function of temperature. The numbers have been obtained as best fits of Eq. (4) to experiments as presented in Fig. 2. Each data point represents the mean value of four independent experiments. The error bars indicate the standard deviation, $\sigma_{\mathrm{n}-1}$, for each group of four experiments.

ible dephosphorylation reaction $\mathrm{P}-\mathrm{E}_{2}\left(\mathrm{~K}_{2}\right) \rightarrow \mathrm{E}_{2}\left(\mathrm{~K}_{2}\right)$ produced an apparent higher affinity for the second binding site. At higher temperatures the state $E_{2}\left(K_{2}\right)$ was "short circuited" into state $\mathrm{P}-\mathrm{E}_{2}$ and prevented an accumulation in state $\mathrm{E}_{2}\left(\mathrm{~K}_{2}\right)$.

Control experiments in the presence of $20 \mu \mathrm{M}$ ATP were performed, in which the transition $\mathrm{E}_{2}\left(\mathrm{~K}_{2}\right) \rightarrow \mathrm{K}_{2} \mathrm{E}_{1}$ was rate limiting with a rate constant of $\leqslant 1 \mathrm{~s}^{-1}$ in the temperature range below $20^{\circ} \mathrm{C}$. Above this temperature no experiments were possible due to artifacts produced by ATP consumption. Since there was virtually no inorganic phosphate present, the back reaction $\mathrm{E}_{2}\left(\mathrm{~K}_{2}\right) \rightarrow \mathrm{P}$ $-\mathrm{E}_{2}\left(\mathrm{~K}_{2}\right)$ could not occur, and even low $\mathrm{K}^{+}$concentrations lead to a significant population of state $E_{2}\left(K_{2}\right)$. This effect should produce an apparently higher affinity for $\mathrm{K}^{+}$as was shown (Table). If experiments were performed in the presence of a high concentration of $\mathrm{P}_{\mathrm{i}}(500$ $\mu \mathrm{M})$ the back reaction $\mathrm{E}_{2}\left(\mathrm{~K}_{2}\right) \rightarrow \mathrm{P}-\mathrm{E}_{2}\left(\mathrm{~K}_{2}\right)$ was sup-

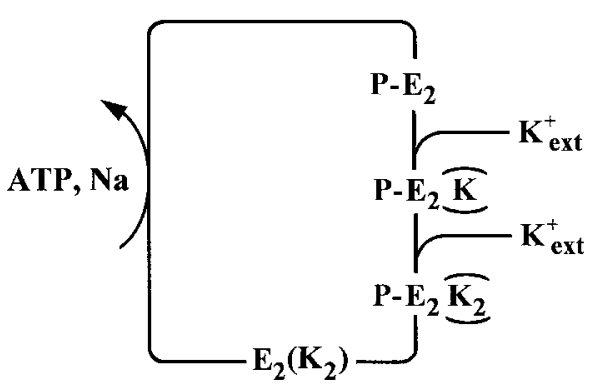

Fig. 4. Simplified Post-Albers cycle with expanded reaction steps of extracellular $\mathrm{K}^{+}$binding. After sequential binding of two $\mathrm{K}^{+}$ions to binding site within the membrane dielectric, the enzyme is spontaneously dephosphorylated. The reactions from state $\mathrm{E}_{2}\left(\mathrm{~K}_{2}\right)$ to $\mathrm{P}-\mathrm{E}_{2}$ are dependent only on ATP and $\mathrm{Na}^{+}$ions which are kept at constant values in an experimental series.

ported and an apparently lower affinity could be observed. The half saturating $\mathrm{K}^{+}$concentration, $c_{1 / 2}$, increased from $0.19 \mathrm{~mm}$ to $0.29 \mathrm{~mm}$ (Table). These observations lead to the suggestion that the obtained apparent $\mathrm{K}^{+}$binding affinities approach the true affinities at high temperatures.

The data presented in this contribution exclude the simultaneous binding of the two cations to the extracellularly presented sites, but are consistent with the notion of two extracellular ion binding sites with equal affinity (Läuger \& Apell, 1986). Since Forbush proved an ordered release of the potassium congener $\mathrm{Rb}^{+}$(Forbush, 1987; Forbush, 1988), an independent access to two separated binding pockets can be excluded in addition. An explanation of sequential binding under this constraint can be proposed by the "flickering gate model" (Forbush, 1987; Läuger, 1991), in which the first $\mathrm{K}^{+}$ion binds with the affinity $K_{1}$ to the first site at the bottom of an ion well, jumps back and forth between the first and second binding site while an occlusion gate flickers between open and close inside the ion well. The second site is not directly accessible from the well. If the gate is open and the first ion bound is placed second, inner binding site, then a second ion can be bound to the first site, directly accessible from the well, with the same affinity as the first ion, $K_{2}=K_{1}$. When both binding sites are occupied, subsequently the dephosphorylation and (permanent) occlusion will occur. In this model different apparent affinities may be observed by influence of subsequent reaction steps, e.g., the rephosphorylation step of the pump in the presence of $\mathrm{P}_{\mathrm{i}}$. In nonequilibrium experiments the rate constants of the flickering process and the jumping of the ion between both sites may easily produce differing apparent binding affinities.

On the basis of the fact that the RH 421 method discriminates only between states with no, one or two ions in the binding sites, but does not between the open or closed flickering gate and between one ion in the fast or slowly accessible site, Forbush's model with eight 
states is reduced to the three-state model according to Eq. (3), in which only the ion-binding steps are under experimental control. With respect to this simplification all presented data and the mathematical modeling (Eq. 3) are in agreement with the model suggested by Forbush (1988).

The authors would like to thank G. Witz for technical assistance. Thi work has been financially supported by the Deutsche Forschungsgemeinschaft (SFB 156)

\section{References}

Apell, H.-J. 1989. Electrogenic properties of the Na,K-pump. J. Mem brane Biol. 110:103-114

Apcll, H.-J., Nelson, M.T., Marcus, M.M., Läuger, P. 1986. Effects of ATP, ADP and inorganic phosphate on the transport rate of the $\mathrm{Na}^{+}, \mathrm{K}^{+}$-pump. Biochim. Biophys. Acta 857:105-115

Bühler, R., Stürmer, W., Apell, H.-J., Läuger, P. 1991. Charge translocation by the Na,K-pump: I. Kinetics of local field changes studied by time-resolved fluorescence measurements. I. Membrane Biol. 121:141-16

Clarke, R.P., Schrimpf. P., Schöneich, M. 1992. Spectroscopic investigations of the potential-sensitive membrane probe $\mathrm{RH} 421$. Biochim. Biophys. Acta 1112:142-152

Forbush III, B. 1987. Rapid release of ${ }^{42} \mathrm{~K}$ and ${ }^{86} \mathrm{Rb}$ from an occluded state of the Na,K-pump in the presence of ATP or ADP. J. Biol Chem. 262:11116-11127

Forbush III, B. 1988. Occluded ions and Na,K-ATPase. In: The $\mathrm{Na}^{+}, \mathrm{K}^{+}$-Pump, Part A: Molecular Aspects. J.C. Skou, J.G. Nørby. A.B. Maunsbach and M. Esmann, editors. Prog. Clin. Biol. Res 268A, pp. 229-248. A.R. Liss, New York.

Gache, C., Rossi, B., Lazdunski, M. 1967. $\left(\mathrm{Na}^{+} . \mathrm{K}^{+}\right)$-activated adenosinetriphosphatase of axonal membranes, cooperativity and control. Eur. J. Biochem. 65:293-306

Glynn, I.M. 1985. The $\mathrm{Na}^{+}, \mathrm{K}^{+}$-transporting adenosine triphosphatase In: The Enzymes of Biological Membranes. A.N. Martonosi, editor Vol. 3 (2nd.), pp. 35-114. Plenum, New York

Glynn, I.M., Richards, D.E. 1982. Occlusion of rubidium ions by the sodium-potassium pump: Its implications for the mechanism of potassium transport. J. Physiol. 330:17-43.

Grinvald, A., Hildesheimer, R., Farber, I.C., Anglister, L. 1982. Im proved fluorescent probes for the measurements of rapid changes in membrane potential. Biophys. J. 39:301-308

Heyse, S., Wuddel, I., Apell, H.-J., Stürmer, W. 1994. Partial reactions of the Na,K-ATPase: Determination of rate constants. J. Gen. Physiol. 104:197-240

Jørgensen, P.L. 1974. Isolation of the $\left(\mathrm{Na}^{+}+\mathrm{K}^{+}\right)$-ATPase. Methods Enzymol. 32:277-290

Karlish. S.J.D., Stein. W.D. 1982. Passive rubidium fluxes mediated by $\mathrm{Na}, \mathrm{K}$-ATPase reconstituted into phospholipid vesicles when ATPand phosphate-free. J. Physiol. 328:295-316

Läuger, P. 1991. In: Electrogenic Ion Pumps. pp. 168-224. Sinauer, Sutherland, MA

Läuger, P.. Apell, H.-J. 1986. A microscopic model for the currentvoltage behavior of the Na,K-pump. Eur. Biophys. J. 13:309-321

Lowry, O.H., Rosenbrough, N.J., Farr, A.L., Randall, R.J. 1951. Protein measurements with the folin phenol reagents. J. Biol. Chem 193:265-275

Marcus, M.M., Apell. H.-J., Roudna, M., Schwendener. R.A., Weder H.-G. and Läuger, P. 1986. $\left(\mathrm{Na}^{+}+\mathrm{K}^{+}\right)$-ATPase in artificial lipi vesicles: influence of lipid structure on pumping rate. Biochim. Biophys. Acta 845:270-278

Rakowski, R.F., Vasilets, L.A., LaTona, J., Schwarz, W. 1991. A negative slope in the current-voltage relationship of the $\mathrm{Na}^{+} / \mathrm{K}^{+}$pump in Xenopus oocytes produced by reduction of external $\left[\mathrm{K}^{+}\right] . J$. Membrane Biol. 121:177-187

Sachs, J.R. 1980. The order of release of sodium and addition of potassium in the sodium-potassium pump reaction mechanism. J. Physiol. 273:489-514

Sachs, J.R., Weit, L.G. 1967. The concentration dependence of active potassium transport in the human red blood cell. J. Clin. Invest. 46:65-76

Sagar, A., Rakowski, R.F. 1994. Access channel model for the voltage dependence of the forward-running $\mathrm{Na}^{+} / \mathrm{K}^{+}$pump. J. Gen. Physiol. (in press)

Schwartz, A., Nagano, K., Nakao, M., Lindenmeyer, G.E., Allen, J.C. 1971. The sodium- and potassium-activated adenosinetriphosphatase system. Methods Pharmacol. 1:361-388

Stürmer, W., Bühler. R., Apell, H.-J., Läuger, P. 1991. Charge translocation by the Na,K-pump: II. Ion binding and release at the extracellular face. J. Membrane Biol. 121:163-176

\section{Appendix}

The relative fluorescence change, $\Delta F / F_{0}$, of $\mathrm{RH} 42 \mathrm{I}$-labeled $\mathrm{Na}, \mathrm{K}$ ATPase fragments at different cation concentrations $[M]$ at the extracellular face can be described by Eq. (4) with the parameters $y_{\infty}, \alpha . K_{\text {। }}$ and $K_{2}$. The assumed reaction scheme is:

$P-E_{2}+2 M \overleftrightarrow{K} P-E_{2} \cdot M+M \overleftrightarrow{K_{2}} P-E_{2} \cdot M_{2}$

We denote the fraction of pump molecules in state $\mathrm{A}$ by $x[A]$ and introduce the following variables:

$\left.x_{0}=x \mid P-E_{2}\right\rfloor, x_{1}=x\left[P-E_{2} \cdot M\left|, x_{2}=x\right| P-E_{2} \cdot M_{2}\right\rfloor, x_{0}+x_{1}+x_{2}=1$

The equilibrium dissociation constants of the two partial reactions are defined by

$K_{1}=\frac{c x_{0}}{x_{1}}, K_{2}=\frac{c x_{1}}{x_{2}}$ with $c \equiv[M]$

When $f_{0}, f_{1}, f_{2}$ are the specific fluorescene levels of the states $\mathbf{P}-\mathrm{E}_{2}$, $\mathrm{P}-\mathrm{E}_{2} \cdot \mathrm{M}$, and $\mathrm{P}-\mathbf{E}_{2} \cdot \mathrm{M}_{2}$, respectively, the total fluorescence, $F$, is calculated by

$F=x_{0} f_{0}+x_{1} f_{1}+x_{2} f_{2}$

and the relative fluorescence change, $\Delta F / F_{0}$ is introduced by

$\frac{\Delta F}{F_{0}}=\frac{F-F_{0}}{F_{0}}$

Under the assumption that the initial state of the protein is the state with no ions bound, $x\left[E_{2} P\right]=1$, the initial fluorescence intensity will be $F_{0}=f_{0}$. This allows the expansion of Eq. (A5)

$\frac{\Delta F}{F_{0}}=\frac{F-f_{0}}{f_{0}}=x_{0}+x_{1} \frac{f_{1}}{f_{0}}+x_{2} \frac{f_{2}}{f_{0}}-1$

Substituting according to Eq. (A3) $x_{1}=\frac{c x_{0}}{K_{1}}, x_{2}=\frac{c x_{1}}{K_{2}}=\frac{c^{2} x_{0}}{K_{1} K_{2}}$ 
and defining $\alpha=\frac{f_{1}-f_{0}}{f_{2}-f_{01}}$

the relative fluorescence change can be expressed as

$\frac{\Delta F}{F_{0}}=x_{0}+x_{0} \frac{\alpha c f_{2}}{K_{1} f_{0}}+x_{0} \frac{c^{2}}{K_{1} K_{2}} \frac{f_{2}}{f_{0}}-1$.

Further substitution of $x_{0}=\frac{1}{1+\frac{c}{K_{1}}+\frac{c^{2}}{K_{1} K_{2}}}$
(A7) and introduction of $F_{\infty}=\frac{f_{2}-f_{0}}{f_{0}}$ as maximum fluorescence change

for the condition, when all enzyme is in state $\mathrm{E}_{2}\left(\mathrm{~K}_{2}\right)$, finally yields in Eq. (4) of the text

$$
\frac{\Delta F}{F_{0}}=F_{\infty} \frac{\frac{\alpha c}{K_{1}}+\frac{c^{2}}{K_{1} K_{2}}}{1+\frac{c}{K_{1}}+\frac{c^{2}}{K_{l} K_{2}}} .
$$

